\title{
Recursos de Alta-Tecnologia Assistiva Disponíveis no Mercado Nacional: ferramentas para alunos com paralisia cerebral'
}

\section{Available Devices of High Assistive Technology in The National Market: tools for the teaching and learning by students with cerebral palsy}

\begin{abstract}
Resumo: No Brasil, tem crescido o interesse sobre a aplicabilidade de recursos de tecnologia assistiva no ambiente escolar para crianças com paralisia cerebral. O objetivo do projeto foi a construção de um banco de dados sobre os recursos de alta tecnologia assistiva existentes no mercado nacional, indicados para o uso no ambiente de sala de aula por crianças com paralisia cerebral, com a finalidade de sistematizar informações, auxiliar na seleção, prescrição e implementação desse tipo de recurso. A partir de uma busca na literatura em sites nacionais existentes sobre o assunto, foi construído um arquivo computadorizado de banco de dados sobre a disponibilidade desses recursos, tendo como parâmetros a metodologia já aplicada em estudo anterior. Assim, foram sistematizadas informações sobre recursos adaptados, constituindo uma fonte de dados acessível a todos os interessados, visando contribuir para a implementação efetiva desses recursos na promoção da escolarização das crianças com paralisia cerebral no país.

Palavras-chave: Tecnologia assistiva. Recursos computacionais. Paralisia cerebral. Inclusão escolar.
\end{abstract}

\begin{abstract}
In Brazil, the interest on the applicability of assistive technology resources in the school environment has grown for children with cerebral palsy, according to the evidences on the difficulties in their process of scholarization. The objective of the project was the construction of a data base about the resources of high assistive technology in the national market, indicated for the use in the classroom environment for children with cerebral palsy, with the purpose to systemize information, to assist in the selection, prescription and implementation of this type of resource. From a search in the literature available in existing national sites, a computerized archive on the availability of these resources was constructed, having as parameters the applied methodology already used in previous study. Therefore, information on adapted resources had been systemized, constituting an accessible source of data to all the interested parties, aiming to contribute for a effective implementation of these resources in the promotion of the scholarization of children with cerebral palsy in the country.

Keywords: Assistive technology. Computational resources. Cerebral palsy. School inclusion.
\end{abstract}

LOURENÇO, Gerusa Ferreira; MENDES, Enicéia Gonçalves; TOYODA, Cristina Yoshie. Recursos de Alta-Tecnologia Assistiva Disponíveis no Mercado Nacional: ferramentas para alunos com paralisia cerebral. I nformática na Educação: teoria e prática, Porto Alegre, v. 15, n. 2, p. 229-245, jul./dez. 2012.

\section{Gerusa Ferreira Lourenço \\ Universidade Federal de São Carlos \\ Enicéia Gonçalves Mendes \\ Universidade Federal de São Carlos \\ Cristina Yoshie Toyoda}

Universidade Estadual Paulista Júlio de Mesquista Filho

\section{I ntrodução}

A educação inclusiva tem se caracterizado como o novo foco de interesse dentro da Educação Especial no Brasil, impulsionada pelo movimento mundial sobre o direito de todos à educação de qualidade e principalmente, a construção de um processo no qual as pessoas excluídas e a sociedade buscam efetivar a equiparação de oportunidades para

\footnotetext{
${ }^{1}$ Esse artigo é referente à monografia de conclusão do curso de Especialização em Intervenção em Neuropediatria da primeira autora (UFSCar/2007) e já foi apresentado em versões preliminares no III Congresso Multidisciplinar em Educação Especial realizado entre os dias 29 e 31 de Outubro de 2007 (UEL/LondrinaPR) e no IV Seminário Acessibilidade, Tecnologia da Informação e Inclusão Digital nos dias 08 e 09 de Novembro de 2007(ATIIDFSP-USP/São Paulo-SP).
} 
todos (MENDES, 2002). Dessa forma, após praticamente um século de iniciativas educacionais aos alunos com necessidades especiais, o Brasil começa a estruturar um respaldo legal com vistas à perspectiva da inclusão escolar, no sentido de se estabelecer metas e caminhos para modificar o sistema educacional para o real atendimento às necessidades educacionais de todos os seus alunos.

Os documentos como a Constituição de 1988 e a Lei de Diretrizes e Bases da Educação (LDB 9394/96) são de grande importância nesse sentido. No entanto, destaca-se a Resolução CNE/CEB no 2/2001, que estabelece as Diretrizes Nacionais para a Educação Especial na Educação Básica (BRASIL, 2001), que direciona para a necessidade de serviços e recursos educacionais especiais no apoio, complemento e suplemento do serviço educacional comum, de modo a prover corpo docente capacitado e especializado, flexibilizações de currículo, emprego de metodologias de ensino específicas, fornecimento de recursos e materiais didáticos especiais, como também a garantia da acessibilidade.

Nessa direção, conforme aponta Mendes (2002), para viabilizar uma política de inclusão escolar de fato é necessário que ações no âmbito organizacional, educacional e pedagógico sejam estabelecidas, o que requer mobilização de diversas esferas de poder, como também modificações econômicas, políticas e culturais.

Confirmando o caminhar bastante lento e complexo desse movimento, a literatura nacional aponta que o despreparo da escola e dos professores, como também a falta de recursos humanos, materiais e dos serviços de apoio são motivos recorrentes mencionados quando sobre as dificuldades para o acesso e permanência do aluno com necessidades especiais dentro da sala de aula comum (MENDES, 2008, MENDES; NUNES; FERREIRA, 2003). Para os alunos com deficiência física, a superação de barreiras físicas para o acesso à escola e ao currículo, assim como também para a participação na dinâmica social escolar têm sido um grande desafio imposto em seu processo de escolarização.

Os resultados do estudo de Lauand (2000) apontam que a qualidade da educação de alunos com deficiência física e múltipla está diretamente ligada a oferta de apoio adequado às demandas do aluno. As dificuldades relacionadas ao acesso à escola e a ausência de adaptações funcionais para a superação de barreiras também esteve presente nas falas de mães de alunos com deficiência física no estudo de Canotilho (2002).

Dentre os alunos com deficiência física, o interesse atual do grupo de pesquisa Formação de Recursos Humanos e Ensino em Educação Especial (GP-FOREESP/UFSCar) é de contribuir para a escolarização de crianças com paralisia cerebral, tendo em vista as dificuldades apontadas na literatura nesse processo e a necessidade da implementação adequada de recursos e adaptações.

A paralisia cerebral se constitui atualmente como a condição mais comum de deficiência física na infância (STANLEY et al., 2000, apud WALTERS et al., 2005). Causada por uma lesão no sistema nervoso central imaturo, ela se caracteriza como um grupo de desordens neurológicas, com predomínio de distúrbios motores e alterações posturais permanentes, com associação freqüente de desordens visuais, auditivas, cognitivas e da comunicação (GAUZZI; FONSECA, 2005, GIANNI, 2003, ZERBINATO; MAKITA; ZERLOTI, 2003). Os 
comprometimentos motores, o tipo de tônus muscular predominante, os distúrbios associados, além das variáveis atuantes no desenvolvimento de ordem social, tem levado a um maior ou menor comprometimento no desempenho funcional dessa criança, influenciando de forma determinante o seu desempenho no contexto educacional (BASIL, 1995, MANCINI et al., 2004).

Com a chegada desse alunado à escola regular nos últimos anos no país, aumentou o interesse por estudos que investigassem como está ocorrendo essa escolarização. Foram realizados estudos como o de Rossi (1999), Alpino (2003), Lauand (2000), Baleotti e Manzini (2002), Mello e Martins (2004), Silveira e Neves (2006), Gomes e Barbosa (2006), Gonçalves (2006), Leão et al. (2006), Melo e Martins (2007) e Silva (2007), e seus resultados confirmam que para o atendimento educacional efetivo a esses alunos é necessário prover tecnologia especializada, como adaptações e estratégias educacionais que visem à acessibilidade desse aluno ao currículo.

Nesse sentido, serviços devem ser estabelecidos para trabalhar em conjunto com a escola, no fornecimento de apoio, na capacitação de recursos humanos, no planejamento educacional, no planejamento de modificações ambientais, na implementação de recursos e adaptações (ALPINO, 2008).

Os recursos de tecnologia assistiva aparecem como ferramentas eficientes de acesso ao currículo quando implementados adequadamente (OKOLO; BOUCK, 2007) e o seu uso tem sido bastante incentivado na escolarização de alunos com necessidades especiais, e dentre deles, os com paralisia cerebral (BRASIL, 2004, MANZINI; DELIBERATO, 2007, BERSH; PELOSI, 2007). O país está em um movimento crescente de investimento teórico e prático para a estruturação de serviços por parte dos órgãos políticos em busca de viabilizar efetivamente esses recursos à população. Leis e decretos estão sendo formulados e um Comitê de Ajudas Técnicas composto por especialistas e representantes de entidades e órgãos públicos foi criado com o intuito de estabelecer metas de ação sobre esses recursos no Brasil.

Com a formação desse Comitê, uma das suas primeiras ações foi estabelecer a definição e terminologia mais adequada para esses recursos na realidade nacional. Assim, conforme aprovado:

Tecnologia assistiva é uma área do conhecimento, de característica interdisciplinar, que engloba produtos, recursos, metodologias, estratégias, práticas e serviços que objetivam promover a funcionalidade, relacionada à atividade e participação, de pessoas com deficiência, incapacidades ou mobilidade reduzida, visando sua autonomia, independência, qualidade de vida e inclusão social. (BRASIL, 2007, linhas 225-230).

Nessa direção, de uma forma ampla, a Tecnologia Assistiva pode ser entendida como um campo que engloba tanto os equipamentos, como também os serviços que promovam ao indivíduo um sucesso maior na realização de atividades, aumentando, mantendo ou melhorando suas capacidades funcionais. Dessa forma, temos os recursos e equipamentos de TA, que podem ser classificados conforme o seu grau de complexidade (alta, média e baixa tecnologia) (COOK; HUSSEY, 2007) e também conforme o seu propósito de uso (LAUAND, 2005). Nesse estudo, vemos o computador e suas possíveis adaptações e equipamentos como recursos que po- 
dem auxiliar os alunos com paralisia cerebral na execução de tarefas no ambiente escolar, principalmente dentro da sala de aula (SANTAROSA, 2000, VALENTE, 2001, BERSCH; PELOSI, 2007), pois sem eles, esses alunos correm o risco de ficarem à margem do processo educacional, pela impossibilidade de comunicação efetiva com o professor.

Lauand (2005) assinala que apesar da existência atual de muitos recursos de tecnologia assistiva disponíveis no mercado nacional, faltam informações sistematizadas sobre como obtê-los, suas finalidades e uso, situação esta que dificulta o acesso dos educadores, profissionais da área da reabilitação e família a esse tipo de informação. Após constatar essa grande lacuna na produção e sistematização de conhecimentos no país, essa autora construiu um banco de dados através da identificação e categorização de todos os recursos de tecnologia assistiva existentes no mercado brasileiro, organizando e sistematizando as informações inerentes aos produtos, propondo-se a facilitar o acesso aos recursos pela população alvo.

No sentido de continuar promovendo a sistematização de informação sobre recursos tecnologia assistiva de modo a auxiliar os profissionais envolvidos na prescrição do recurso mais adequado para as demandas do ambiente escolar, além de promover uma atualização na fonte de informações construída por Lauand (2005), o objetivo da presente investigação foi de sistematizar informações sobre a disponibilidade, características e formas de obtenção dos recursos classificados como alta tecnologia assistiva, tendo como parâmetros o estudo de Lauand (2005). Os recursos de alta tecnologia assistiva são aqueles considerados mais complexos, mul- tifuncionais, geralmente envolvendo sistemas computadorizados, operados através de programas como softwares, o que requer um maior investimento para a aquisição e para o processo de implementação.

A opção em seguir o estudo de Lauand (2005) ocorreu por três principais motivos. Primeiramente por dar continuidade dentro do grupo de pesquisa ao trabalho iniciado por ela com relação à sistematização de informações sobre recursos de tecnologia assistiva na realidade brasileira, buscando a maior aplicabilidade dentro do universo educacional do país. Segundo, pelo ineditismo do trabaIho de taxonomia dos recursos, classificandoos conforme as características de uso, pois todas as outras formas de classificação dos tipos de recursos presentes na literatura nacional são advindas da simples tradução de sistemas categoriais internacionais. Por fim, acreditou-se na necessidade de recorte e atualização do banco especificamente para a população de alunos com paralisia cerebral no que dizia respeito aos recursos computacionais possíveis de serem utilizados no ambiente de sala de aula, devido ao avanço rápido de desenvolvimento nessa área tecnológica e a ampliação gradual da facilidade de importação dos recursos.

\section{Método}

O método proposto se baseou em uma pesquisa de levantamento de natureza descritiva, buscando-se coletar, descrever e armazenar informações sobre os recursos de alta tecnologia assistiva que possam ser implementados no ambiente de sala de aula, 
com a finalidade de produzir e disseminar esse banco de dados.

O estudo de Lauand (2005) foi estruturado em três etapas: criação de um sistema de classificação de recursos de tecnologia assistiva baseado no National Classification System for Assistive Technology Devices and Services / EUA (2000), busca e classificação de informações sobre os recursos que se encontravam disponíveis para aquisição no mercado nacional e elaboração de um banco de dados. Os recursos encontrados pela citada autora foram categorizados e catalogados em nove diferentes agrupamentos, a saber:

- Dispositivos e acessórios computacionais especiais: utilitário e acessórios para o computador.

- Mobilidade: equipamentos e/ou recursos para mobilidade e posicionamento.

- Elementos sensoriais: recursos aplicados em casos de deficiências sensoriais como a baixa visão e a surdez.

- Adaptações para atividades de vida diária: recursos para independência / autonomia pessoal nas atividades do cotidiano.

- Adaptações pedagógicas: adaptações de baixo custo para atividades de leitura, escrita e desenho.

- Elementos arquitetônicos: adaptações estruturais no ambiente.

- Mobiliário e equipamentos modificados: mobiliário e equipamentos modificados ou feitos sob medida.

- Controles ambientais: sistemas de controle e modificações do ambiente.

- Lazer/ Recreação/ Esportes: recursos para atividades de lazer, recreação e esportes.
Como o objetivo dessa pesquisa foi a construção de um banco de dados exclusivo sobre recursos de alta tecnologia assistiva para o ambiente escolar, optou-se por enforcar apenas a categoria Dispositivos e Acessórios Computacionais Especiais, que representou 9\% dos recursos encontrados e cadastrados por Lauand (2005).

Heller (2003, apud LAUAND, 2005) aponta três categorias de tecnologia assistiva para computadores que são as mais utilizadas para alunos com deficiências físicas e múltiplas: as modificações de entrada da informação (input), as modificações de saída da informação (output) e os apoios de processamento das informações. Lauand (2005) se apoiou nesse referencial teórico para determinar as quatro subcategorias dentro de Dispositivos e Acessórios Computacionais Especiais, que são: Equipamentos de entrada e saída de informação do computador, Softwares especiais, Acessórios para o computador e Calculadoras especiais.

Os recursos de entrada da informação (input) são definidos como recursos que irão inserir informações para o computador. Assim são considerados recursos de input diversos tipos de teclado, mouses, acionadores, drivers de disquete e CD-Room, scanner e alguns tipos de softwares. Os recursos de saída da informação (output) são equipamentos como o monitor e a impressora.

Os apoios para o processamento de informações foram catalogados dentro da subcategoria Softwares Especiais, e tratam-se de programas especiais cujo objetivo é facilitar o uso das aplicações informáticas em geral, como os softwares de leitura de tela, programas de predição de palavras e os simuladores de teclado ou teclados virtuais. 
A subcategoria Outros Acessórios engloba os demais recursos utilizados para aprimorar o uso do computador, como os apoios para punho, os sobreteclados de acrílico para isolamento de teclas e o apoio para o monitor.

A última subcategoria proposta é formada pelas calculadoras especiais que realizam as mesmas funções de uma calculadora padrão e de calculadoras científicas e podem ser utilizadas para a execução dos diversos tipos de operações matemáticas.

É importante ressaltar que para o presente estudo manteve-se a busca pelos recursos da subcategoria Outros Acessórios apesar de eles não serem de alta tecnologia. Essa opção foi escolhida porque os referidos acessórios interferem positivamente durante o uso dos recursos de informática por pessoas com disfunção neuromotora, como no caso das seqüelas de paralisia cerebral. A maioria dos recursos cadastrados nessa subcategoria, na verdade, são equipamentos que podem ser utilizados por qualquer pessoa, elaborados, muitas vezes, para facilitar o uso do computador, dadas às suas características ergonômicas.

Tomando como base a metodologia de Lauand (2005), a primeira etapa da pesquisa foi a construção de uma ficha de identificação do recurso para que as informações coletadas sobre eles pudessem ser registradas conforme a sub-categoria, grau de complexidade do equipamento e características de funcionamento, média de custo e disponibilidade no mercado brasileiro.

Com a ficha de identificação finalizada, foi dado início à busca pelos recursos através de consultas a bibliotecas virtuais, sites de busca na Internet, sites especializados sobre reabilitação, sites de representantes comerciais dos equipamentos e publicações especializadas impressas. A busca foi realizada para a localização dos recursos de alta tecnologia assistiva disponíveis no mercado nacional, identificando e selecionando os recursos a serem utilizados no ambiente escolar, mais especificamente nas atividades dentro da sala de aula. Desta forma, não foram selecionados, portanto, os recursos de mobilidade, atividade de vida diária e esporte/lazer por crianças com paralisia cerebral. Foram buscados itens que pudessem ser classificados dentro da categoria Dispositivos e acessórios computacionais especiais como definida por Lauand (2005).

Após a realização desse estudo sobre as características dos recursos que deveriam compor o banco, deu-se início a próxima etapa da pesquisa: a busca pelos recursos. A opção por reproduzir essa metodologia foi determinada por ela ter se mostrado um método eficaz já no estudo de referência.

Para a localização dos recursos nos sites de busca foram utilizados descritores mais generalizados como tecnologia assistiva, recursos assistivos, ajudas técnicas, recursos computacionais, e também descritores específicos conforme o equipamento que estava sendo buscado: teclado adaptado, mouse, softwares especiais, etc. Foram inúmeros os descritores utilizados na busca, os quais, de modo dinâmico, indicavam novos descritores que localizavam o material a ser investigado.

À medida que os recursos foram localizados, as fichas de identificação foram sendo preenchidas, como exemplo em anexo. O modelo inicial de ficha de identificação contava com os seguintes campos: nome do recurso, categoria, subcategoria, indicações, caracte- 
rísticas de funcionamento, média de custo, fontes/disponibilidade e foto/ilustração.

Nos campos categoria e subcategoria, priorizou-se cadastrar os recursos conforme Lauand (2005). Assim, as subcategorias criadas por Lauand (2005) tornaram-se as categorias aqui utilizadas. E novas subcategorias foram criadas para os recursos referentes à entrada e saída de informações no computador (recursos de input e output), como Teclado Adaptados, Mouse Adaptado, Acionadores, Tela Sensível ao Toque, conforme o propósito do equipamento.

Os campos indicações e características de funcionamento foram preenchidos em grande parte com informações fornecidas pelos próprios revendedores dos produtos. No entanto, conforme as fichas foram sendo completadas, notou-se que algumas informações estavam redundantes ou duplicadas.

No campo indicações, os dados que estavam sendo inseridos tinham duas características: informações sobre para o que se destinava o recurso e informações sobre a população alvo. Dessa forma, percebeu-se que as informações sobre para o que servia o recurso já estavam sendo mencionadas no próprio nome do recurso ou mesmo na categoria que estava sendo alocado, e com relação à população alvo, a busca pelo recurso já estava sendo feita visando o uso por alunos com paralisia cerebral, tornando-se redundante caracterizar o recurso com relação a isso.

Assim, priorizou-se manter o campo características de funcionamento enriquecido com informações mais detalhadas sobre o produto. Esse maior detalhamento foi possível através de uma análise sobre o uso do recurso realizada pela própria pesquisadora. Dessa forma, puderam ser inseridas neste campo informações sobre a complexidade, bem como adequação e prontidão para sua utilização.

O campo média de custo foi preenchido a partir de informações encontradas nos sites de venda dos equipamentos. Não se teve a intenção de realizar a publicidade ou a indicação de compra em determinado local. O objetivo desse campo é apenas dar uma noção indicativa do investimento financeiro atual necessário para a aquisição do recurso, dado este imprescindível durante o planejamento da implementação do recurso. Alguns cadastros não contêm essas informações por não terem sido disponibilizadas no momento da busca do recurso. Para esses recursos o campo foi preenchido com a informação sob consulta.

No campo disponibilidade foram alocados os endereços eletrônicos dos revendedores e fabricantes dos recursos como fonte de contato para a compra. Alguns recursos, principalmente da categoria Outros Acessórios possuem diversas opções de locais para aquisição. Então, nesses casos priorizou-se informar alguns exemplos de sites onde podem ser encontrados.

Por fim, o último campo Foto ou Ilustração, teve como intuito permitir uma visualização de como é o recurso e uma compreensão melhor dos dados que estão contidos no campo características de funcionamento.

Após o término da busca pelos recursos, o banco de dados propriamente dito foi construído através da digitalização das fichas de identificação dos recursos preenchidas na etapa anterior em um banco de dados criado a partir de tabelas no software Microsoft Word ${ }^{\circledR}$. A princípio, a intenção era construir o banco de dados digital a partir do software 
Microsoft Access ${ }^{\circledR}$ (2003), como no estudo efetuado por Lauand (2005). No entanto, optou-se por utilizar o próprio software Microsoft Word ${ }^{\circledR}$ (2003), construindo um banco de dados composto por tabelas seqüenciais. Essa opção ocorreu porque a disponibilização via digital do arquivo é preferível em formato pdf e visualmente ficaria mais acessível ao público se o arquivo fosse feito na forma de um texto. Algumas possibilidades e ferramentas de busca que são características e possíveis dentro do software Microsoft Access ${ }^{\circledR}$ (2003) para a consulta ao banco, não ficaram disponíveis a partir desse novo formato, sendo que no software leitor de arquivos em formato pdf, a busca pode ser realizada através de localização de palavras-chave.

Dada por encerrada a busca e a inserção de dados no banco, deu-se início à fase de análise do material organizado, contabilizando o número dos recursos encontrados em cada subcategoria, os tipos, o nível de complexidade e o custo para obtenção.

O banco foi finalizado em um documento do tipo pdf.

\section{Resultados e Discussão}

O banco de dados construído totalizou 50 recursos localizados no mercado nacional. Foram cadastrados equipamentos em três categorias: recursos de entrada e saída de informações com as subcategorias teclados adaptados, mouse adaptado e acionadores; softwares especiais; e outros acessórios, sendo que o maior número de recursos foi encontrado para a primeira categoria, corroborando com estudo de Lauand (2005).
É importante ressaltar que a comparação com o número de itens encontrados e cadastrados por Lauand (2005) (totalizando 39 na categoria Dispositivos e Acessórios Computacionais Especiais) não pode ser realizada de forma direta sobre cada uma das categorias nesse trabalho, pois não foi possível ter acesso aos produtos cadastrados, mas apenas a seus tipos e categorias. Além disso, no somatório final dos produtos encontrados por Lauand (2005) nessa grande categoria, não há separação com os recursos para utilização por pessoas com outros tipos de deficiências, como por exemplo, os softwares de leitura e a impressora em Braille, fora do escopo dessa pesquisa.

Então, para a comparação dos resultados dessa pesquisa com o estudo de Lauand (2005), baseou-se uma estimativa do que foi apresentado no decorrer do seu trabalho, mencionando os tipos de recursos que foram ou não encontrados. A apresentação a seguir dos equipamentos encontrados e cadastrados estará dividida conforme as categorias utilizadas. É importante ressaltar que as demais informações sobre os recursos, como os nomes comerciais, sites de revendedores e imagens diretas dos equipamentos compõem as informações no banco de dados, o qual pode ser obtido em contato direto com os autores do artigo e também no site do grupo de pesquisa².

\subsection{Recursos de Entrada e Saída de In- formação}

Dentro dos recursos de entrada e saída de informação foram localizados equipamen-

\footnotetext{
2 Endereço eletrônico: <http://ufscar.br/gpforeesp>
} 
tos como teclados adaptados, mouses especiais, acionadores e monitores especiais. Alguns equipamentos característicos dessa categoria não foram priorizados no banco de dados. Esses equipamentos são os considerados padrões ou convencionais, sendo que para a inclusão no banco, deu-se preferência aos equipamentos diferenciados, que possuíssem alguma característica que, de alguma forma, poderiam vir a favorecer o acesso ao computador por pessoas com paralisia cerebral. Neste sentido, os equipamentos considerados padrões como os monitores convencionais ( $L C D$ e CRT), as impressoras (jato de tinta, laser, matricial e multifuncional), os scanners, o teclado e o mouse padrões não foram cadastrados no banco de dados.

Cook e Hussey (2002, apud LAUAND, 2005) caracterizam os recursos de entrada de informação no computador com relação à forma de acesso que eles permitem. Assim, são considerados equipamentos de seleção direta (ou seja, aqueles que permitem diretamente selecionar determinada função no computador) os teclados, mouses e telas sensíveis ao toque, e os de seleção indireta (aqueles que juntamente com um software permitem a seleção de determinada função) os acionadores.

\subsubsection{Equipamentos de seleção direta}

Os tipos de teclados adaptados cadastrados no banco são: teclado sensível ao toque, com lâminas possíveis de serem personalizadas; teclado ergonômico com disposição diferenciada das teclas preconizando o bem-estar biomecânico do corpo do usuário; teclado especial para o uso em determinados softwa- res de jogos infantis; teclado colorido em tamanho padrão com 101 teclas; teclados em tamanho padrão confeccionado em material emborrachado; teclado projetado em laser e caderno digital.

No mercado nacional foram encontrados dois modelos de teclados expandidos e um de teclado reduzido, sendo que para Lauand (2005) esses tipos de teclados eram pouco disponíveis no país, estando mais a cargo da confecção personalizada, sob encomenda.

Sobre os mouses adaptados, foram cadastrados recursos dos tipos: mouse adaptado com três teclas grandes para a função dos cliques do mouse; mouse adaptado com dois roletes que quando acionados direcionam o cursor do mouse e mais três teclas para os cliques; mouse adaptado que permite o funcionamento de acionadores substituindo a função da tecla esquerda do mouse; mouse por movimento dos olhos e da cabeça; TrackBall.

No estudo de Lauand (2005) não foram encontrados no mercado nacional os mouses por movimento da cabeça, o TrackBall, as ponteira luminosas, os mouses pelo piscar dos olhos e pelos movimentos aéreos da mão. Desses, os mouses por movimento da cabeça e os TrackBall já estão sendo comercializados, sendo inclusive fabricação nacional.

Vale ressaltar que existe ainda a possibilidade de utilizar o teclado numérico do teclado convencional para as funções do mouse quando se está trabalhando em ambiente Windows, a partir de configurações em Opções de Acessibilidade do próprio software.

A última forma de seleção direta mencionada são as telas sensíveis ao toque. Esse tipo de dispositivo, com tecnologia touchs- 
creen, já pode ser encontrado no Brasil, em duas versões: em vidro e cristal. Além das telas, outros dispositivos com essa tecnologia estão sendo comercializados. São eles: as mesas digitalizadoras, os projetores que transformam uma lousa branca em uma tela reconhecida pelo computador, e os monitores com telas sensíveis ao toque também já comercializados em diversas formas e tamanhos.

\subsubsection{Equipamentos de seleção indireta}

Os acionadores foram os equipamentos mais encontrados para comercialização no país. Lauand (2005) aponta ter encontrado apenas acionadores do tipo por pressão na época de seu levantamento, mas atualmente já é possível localizar além dos acionadores por pressão (dos mais variados tipos, formas, tamanhos, de fabricação nacional e importados), os acionadores por alavanca, com destaque para o acionador em haste e o com cordão. Os acionadores de mercúrio, magnético de dedo, de sucção / sopro e o por sombra continuam ausentes no mercado nacional. Alguns estudos em andamento no país, em parcerias entre as áreas da saúde e da engenharia elétrica, estão sendo desenvolvidos e implementados diferentes tipos de acionadores, como o de sopro para o acionamento do computador.

\subsubsection{Equipamentos de saída de infor- mações}

Além de equipamentos como o monitor sensível ao toque, não foi localizado no mercado nacional nenhum outro tipo que tivesse uma característica especial que o diferenciasse dos considerados convencionais.

\subsection{Softwares Especiais}

A segunda categoria cadastrada foi a que dizia respeito aos softwares que permitem ao usuário com paralisia cerebral acessar e executar funções no computador de forma mais adequada. Lauand (2005) assinalou que os softwares com propósitos especiais mais conhecidos são os leitores de tela (utilizados principalmente por deficientes visuais), os programas de predição de palavras e os simuladores de teclado ou teclados virtuais.

No presente estudo, foi possível localizar e cadastrar os seguintes tipos de softwares: simuladores de teclado; softwares de predição de palavras; softwares para desenvolver a comunicação alternativa; softwares para construção de pranchas de comunicação e teclados personalizados; além de softwares para ativação das funções do computador via comando de voz.

Alguns deles foram desenvolvidos por pesquisadores brasileiros e podem ser adquiridos gratuitamente. Destaca-se que no estudo de Lauand (2005) não foram localizados no país os programas de predição de palavras, bastante utilizados no exterior (ANSON et al., 2006), mas que atualmente já tem algumas versões disponíveis.

Dentre todos os tipos de softwares localizados, consideram-se os mais complexos para o uso são os de comando por voz, pois requerem uma grande fase de treinamento do usuário. Em seguida vêm os softwares importados por apresentarem os manuais em outro idioma. 


\subsection{Outros Acessórios}

A última categoria cadastrada no banco engloba os equipamentos considerados como outros acessórios que podem vir a aprimorar o uso do computador pelas pessoas com paralisia cerebral. Essa categoria é bastante diversificada, tendo equipamentos para auxiliar a digitação, apoios, etc.

No banco foram cadastrados os seguintes tipos de produtos: ponteiras para digitação com apoio na mão e na cabeça; sobreteclados de acrílico (colméia) para teclado padrão e especial; chaveador para uso com os mouses adaptados; microfone; suporte para pés; apoio para antebraço; descanso para punho; braço regulável para posicionamento do monitor.

\subsection{Calculadoras Especiais}

Apesar de essa ser uma categoria do banco de Lauand (2005), no presente banco não foi cadastrado nenhum recurso desse tipo, uma vez que não foi possível localizar nenhum equipamento que apresentasse variações do que já é considerado convencional. Considera-se importante expor que no mercado existem disponibilizados diversos tipos de calculadoras eletrônicas, possíveis de serem utilizadas para execução de funções matemáticas, construções de gráficos, etc. E que deve ficar a cargo dos profissionais envolvidos com a implementação de recursos, buscarem uma calculadora que atenda às demandas dos alunos com paralisia cerebral. O banco está disponível a todos os interessados que o poderão solicitar via e-mail à primeira autora do artigo.

\section{Conclusões}

O estudo realizado possibilitou localizar e catalogar uma gama de recursos existentes no mercado nacional que podem ser utilizados para melhorar o processo de escolarização de alunos com paralisia cerebral através do computador. Vale ressaltar que outros recursos que atendem a demandas dessa população já estão disponíveis no mercado e não compuseram o banco em seu momento de construção. Porém, há no grupo de pesquisa um investimento de alimentação constante desse catálogo de modo a mantê-lo atualizado.

O objetivo principal desse banco é possibilitar aos profissionais da área da reabilitação e demais interessados como professores e pais, uma fonte de informações atual sobre quais são os recursos que estão disponíveis no Brasil para serem implementados junto aos alunos. Sabe-se que esse processo de implementação é complexo e envolve muitas etapas de avaliação e treino. No entanto, acredita-se que ter conhecimento dos recursos que se tem acesso no país é um passo importante para o início desse planejamento.

Durante as etapas de construção as dificuldades encontradas foram mínimas e surgiram somente quando se buscou por determinados equipamentos. A maioria foi de fácil localização, mesmo via Internet, o que corrobora para a idéia já apontada por Lauand (2005) de que o desenvolvimento e a disponibilização desse tipo de tecnologia assistiva estão em ascensão no país, apesar dele ainda estar em estágio inicial quando comparado a países desenvolvidos, e em fontes variadas e 
multidisciplinares, o que requer centralizar e sistematização das informações.

Com relação às conclusões sobre os recursos do banco, pode-se afirmar que os equipamentos encontrados são mais diversificados do que no primeiro estudo de levantamento feito por Lauand (2005), em diferentes tipos e graus de complexidade, o que pode indicar que o investimento nesse tipo de equipamento tem aumentado, mobilizando tanto o maior número de importações como também o interesse pelo desenvolvimento nacional desta área no país.

Sobre as características de complexidade e custo, de uma forma geral todos os recursos encontrados apresentaram baixa complexidade desde o momento de instalação, sendo os da categoria Softwares Especiais os que requerem maior atenção e treinamento para o uso. Sobre o custo, ele ainda pode ser considerado como um alto investimento, porém com a fabricação de recursos nacionais, esse custo tende a abaixar com o passar dos anos e à medida que mais usuários tenham acesso aos mesmos.

Espera-se que com a sistematização dessas informações em formato de um arquivo digital de fácil leitura e entendimento, possibilite socializar uma fonte de dados importante e adequada a todos os interessados e promovido uma colaboração para a melhora do processo de viabilização desses recursos no ambiente escolar para alunos com paralisia cerebral. Uma vez que os profissionais passem a conhecer o que há disponível, acredita-se em um modelo circular, onde o uso cada vez mais adequado dos equipamentos promoverá o maior interesse e investimentos na busca pelos recursos, o que determinará um fluxo de maior disponibilidade no mercado, afetando afetar o custo e o uso dos equipamentos. A ampliação da oferta poderá diminuir o curso e, quanto menor o custo, mais alunos poderão ter acesso a esses equipamentos e favorecer a participação na sala de aula.

Por fim, vale ressaltar que entendemos a complexidade de se pensar na inserção de um recurso tecnológico, cujo custo é elevado para realidades educacionais que sequer não dão conta nem das necessidades básicas. No entanto, acreditamos que devemos direcionar forças e instrumentalizar os profissionais para criar possibilidades para a escolarização efetiva de todos os alunos e conscientizar pessoas com deficiências e suas famílias que o acesso a tais recursos é que garantirá o direito a uma educação devida para estudantes com necessidades educacionais especiais.

\section{Referências}

ALPINO, A.M.S. O Aluno com Paralisia Cerebral no Ensino Regular: ator ou expectador do processo educacional? 2003. Dissertação (Mestrado em Educação do Individuo Especial) - Universidade Federal de São Carlos, 2003, São Carlos, BR-SP. 
ALPINO, A.M.S. Consultoria Colaborativa do Fisioterapeuta J unto à Escola Comum: mobilidade e participação do aluno com paralisia cerebral em questão. 2008. Tese (Doutorado em Educação Especial) - Universidade Federal de São Carlos, 2008, São Carlos, BR-SP.

ANSON, D. et al. The effects of word completion and word prediction on typing rates using on-screen keyboards. Assistive Technology, Arlington, v. 18, n. 2, p. 146-154, fall 2006.

BALEOTTI, L.R.; MANZINI, E.J. Experiência Escolar do Aluno com Deficiência Física no Ensino Comum: o ponto de vista do aluno. In: MARQUEZI NE, M.C. et al. Inclusão. Londrina: Eduel, 2003. p. 201-213. (Coleção Perspectivas Multidisciplinares em Educação Especial).

BASIL, C. Os Alunos com Paralisia Cerebral: desenvolvimento e educação. In: COLL, G.; PALACIOS, J.; MARCHESI, A. (Org.). Desenvolvimento Psicológico e Educação: necessidades educativas especiais e aprendizagem escolar. Porto Alegre: Artes Médicas, 1995. P. 252-271.

BERSCH, R.C.R.; PELOSI, M.B. Portal de Ajudas Técnicas Para Educação: equipamento e material pedagógico para educação, capacitação e recreação da pessoa com deficiência física: tecnologia assistiva: recursos de acessibilidade ao computador. Brasília: ABPEE, MEC/SEESP, 2007.

BRASIL. Conselho Nacional de Educação. Câmara de Educação Básica. Resolução CNE/CEB 2/2001. Diretrizes nacionais Para a Educação Especial na Educação Básica. Diário Oficial da União, Brasília, 14 set. 2001. Seção 1E, p. 39-40.

BRASIL. Coordenadoria Nacional Para Integração da Pessoa Portadora de Deficiência. Comitê de Ajudas Técnicas. Ata da III Reunião do Comitê de Ajudas Técnicas. 2007. Disponível em: <http://portal.mj.gov. br/corde/comite.asp> Acesso em: 14 jul. 2009.

BRASIL. Ministério Público Federal. Procuradoria Federal dos Direitos dos Cidadãos. O Acesso de Pessoas com Deficiência às Classes e Escolas Comuns da Rede Regular de Ensino. Brasília, 2004.

CANOTILHO, M.M. A Integração de Crianças Portadoras de Deficiência Física no Ensino Regular Segundo a Perspectiva de Seus Pais. Revista Brasileira de Educação Especial, Marília, v. 8, n. 1, p. 15-26, 2002.

COOK, A.M.; HUSSEY, S.M. Assistive technologies: principals and practice. 2. ed. St. Louis, Missouri: Mosby, 2002.

GAUZZI, L.D.V.; FONSECA, L.F. Classificação da Paralisia Cerebral. In: LIMA, C.L.F.A.; FONSECA, L.F. Paralisia Cerebral: neurologia, ortopedia, reabilitação. Rio de Janeiro: Guanabara Koogan, 2004. P. 37-44. 
GIANNI, M.A. Paralisia Cerebral. In: TEIXEIRA, E. et al. Terapia Ocupacional na Reabilitação Física. São Paulo: Ed. Roca, 2003. P. 89-100.

GOMES, C.; BARBOSA, A.J.G. Inclusão Escolar do Portador de Paralisia Cerebral: atitudes de professores do ensino fundamental. Revista Brasileira de Educação Especial, Marília, v. 12, n. 1, p. 85-100, 2006.

GONÇALVES, A.K.S. Estratégias Pedagógicas Inclusivas Para Crianças com Paralisia Cerebral na Perspectiva na Educação Infantil. 2006. Dissertação (Mestrado em Educação do Indivíduo Especial) - Universidade Federal de São Carlos, 2006, São Carlos, BR-SP.

LAUAND, G.B.A. Acessibilidade e Formação Continuada na Inserção de Portadores de Deficiências Físicas e Múltiplas na Escola Regular. 2000. Dissertação (Mestrado em Educação do Indivíduo Especial) - Universidade Federal de São Carlos, 2000, São Carlos, BR-SP.

LAUAND, G.B.A. Fontes de Informação Sobre Tecnologia Assistiva Para Favorecer a Inclusão Escolar de Alunos com Necessidades Especiais. 2005. Tese (Doutorado em Educação do Indivíduo Especial) - Universidade Federal de São Carlos, 2005, São Carlos, BR-SP.

LEÃO, A.M. de C. et al. Inclusão do Aluno com Dismotria Cerebral Ontogenética: análise das práticas pedagógicas. Revista Brasileira de Educação Especial, Marília, v. 12, n. 2, p. 169-186, maio/ago. 2006.

MANCINI, M.C. et al. Gravidade da Paralisia Cerebral e Desempenho Funcional. Revista Brasileira de Fisioterapia, São Carlos, n. 8, n. 3, p. 253-260, 2004.

MANZINI, E.J .; DELIBERATO, D. Portal de Ajudas Técnicas Para Educação: equipamento e material pedagógico especial para educação, capacitação e recreação da pessoa com deficiência física. Brasília: MEC, 2007. V. 4.

MELO, F.R.L.V.; MARTINS, L.A.R. Acolhendo e Atuando com Alunos que Apresentam Paralisia Cerebral na Classe Regular: a organização da escola. Revista Brasileira de Educação Especial, Marília, v. 13, n. 1, p. 111-130, jan./abr. 2007.

MENDES, E.G. Perspectivas Para a Construção da Escola Inclusiva. In: PALHARES, M.S.; MARINS, S. Escola Inclusiva. São Carlos: Edufscar, 2002. P. 61-86.

MENDES, E.G. Construindo um Lócus de Pesquisa Sobre Inclusão Escolar. In: MENDES, E.G.; ALMEIDA, M.A.; WILLIAMS, L.C.A. Temas em Educação Especial: avanços recentes. 1. ed. São Carlos: EDUFSCar, 2004. P. 221-230. 
MENDES, E.G. Pesquisas Sobre Inclusão Escolar: revisão da agenda de um grupo de pesquisa. Revista Eletrônica de Educação: revista bilíngüe do Programa de Pós-Graduação em Educação da Universidade Federal de São Carlos, São Carlos, v. 2, n. 1, 2008. Disponível em: <http://www. reveduc.ufscar.br/index. php?option=com_content\&task=view\&id=46\&l temid=1> Acessado em: 22 jul. 2008.

OKOLO, C.M.; BOUCK, E.C. Research about assistive technology: 2000-2006: what have we learned? Journal of Special Education Technology, Arlington, VA, v. 22, n. 3, p. 19-33, 2007.

ROSSI, L.S.P.A. Os Caminhos e Descaminhos da Educação da Criança com Paralisia Cerebral: pais-crianças-professores. 1999. Dissertação (Mestrado) - Centro Sarah de Formação e Pesquisa, Universidade Sarah de Ciências de Reabilitação, 1999, Brasília, BR-DF.

SANTAROSA, L.M.C. Simulador de Teclado Para Portadores de Paralisia Cerebral: avaliação e adaptação para português. In: ACCIONES de cooperación en ciencia y tecnologia con incidencia en la mejora de la calidad de vida de la infancia y la adolescencia iberoamericanas. Madrid: ALBA, 2000. V. 1, p. 31-40.

SILVA, D.B.R. Avaliação das Atividades de Crianças com Paralisia Cerebral na Escola Regular: participação, níveis de auxílio e desempenho. 2007. Dissertação (Mestrado em Educação do Indivíduo Especial) - Universidade Federal de São Carlos, 2007, São Carlos, BR-SP.

SILVEIRA, F.F.; NEVES, M.M.B.J. Inclusão Escolar de Crianças com Deficiência Múltipla: concepções de pais e professores. Psicologia: teoria e pesquisa, v. 22, n. 1, p. 79-88, jan./abr. 2006.

VALENTE, J.A. Liberando a Mente: computadores na educação especial. Campinas: Ed. Unicamp, 1991.

WATERS, E. et al. Development or a condition-specific measure of quality of life for children with cerebral palsy: empirical thematic data reported by parents and children. Child Care, Helth \& Development, Oxford, v. 31, n. 2, p. 127-135, 2005.

ZERBINATO, L.; MAKITA, L.; ZERLOTI, P. Paralisia Cerebral. In: TEIXEIRA, E. et al. Terapia Ocupacional na Reabilitação Física. São Paulo: Ed. Roca, 2003. P. 505-534. 


\section{Gerusa Ferreira Lourenço}

Terapeuta Ocupacional. Doutora em Educação Especial PPEGEEs/UFSCar; Docente do Departamento de Terapia Ocupacional/ Universidade Federal de São Carlos-SP - E-mail: gerusalourenco@gmail.com.

\section{Enicéia Gonçalves Mendes}

Psicóloga. Doutora em Psicologia Experimental IP/USP; Docente do Departamento de Psicologia/ Universidade Federal de São Carlos-SP - E-mail: egmendes@ufscar.br.

\section{Cristina Yoshie Toyoda}

Terapeuta Ocupacional. Doutora em Psicologia Experimental IP/USP; Docente do Departamento de Fisioterapia e Terapia Ocupacional/ Universidade Estadual Paulista Júlio de Mesquista Filho - Campus Marília-SP - E-mail: cristoyoda@gmail. com 


\section{ANEXO}

\section{Exemplo de Ficha de Identificação Preenchida}

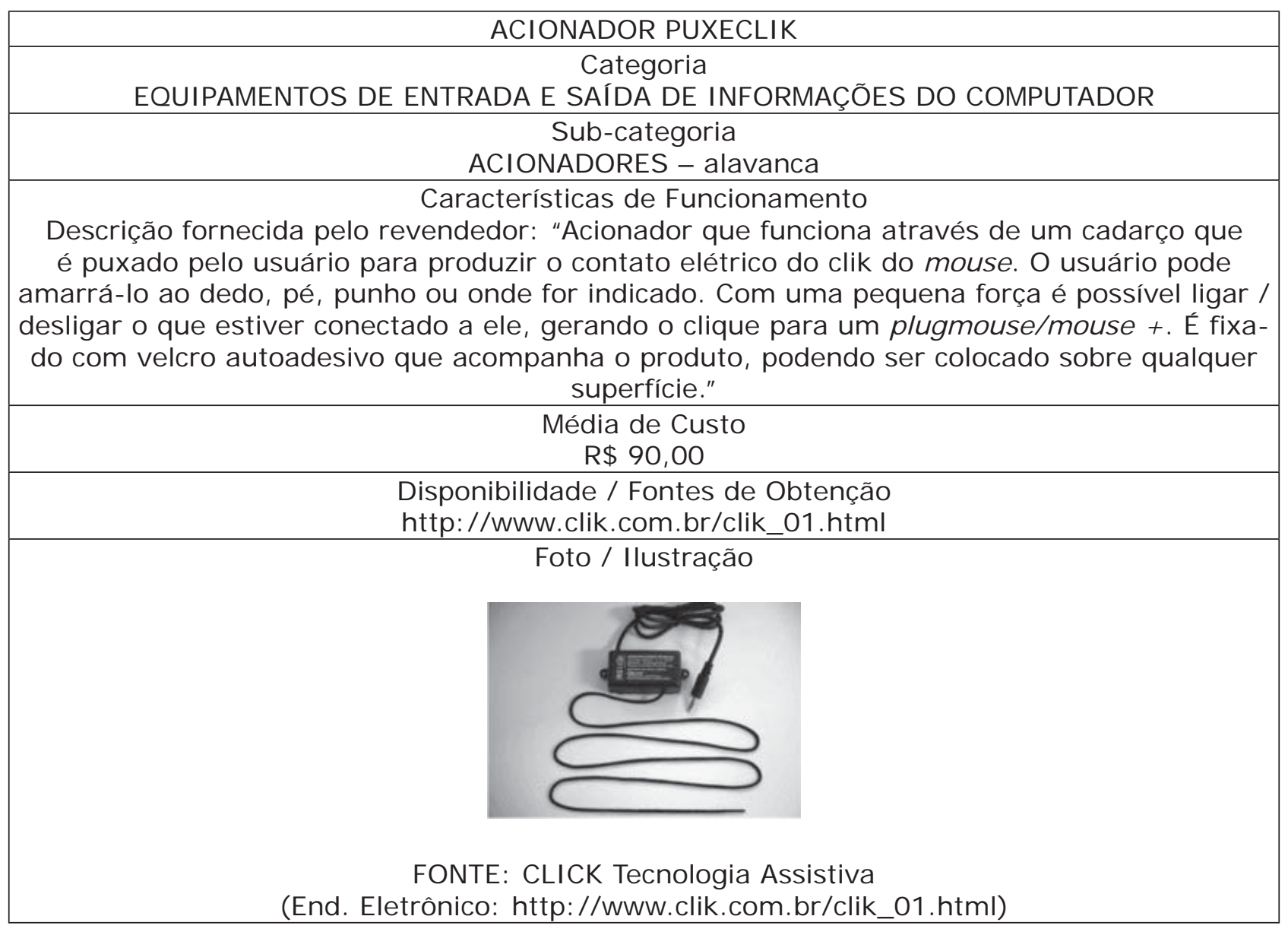

